\title{
Laminar Convection in a Uniformly Heated Vertical Porous Channel Revisited
}

\author{
Basant K. Jha, Michael O. Oni \\ Department of Mathematics, Ahmadu Bello University, Zaria, Nigeria \\ Email address: \\ basant777@yahoo.co.uk (B. K. Jha), michaeloni29@yahoo.com (M. O. Oni)
}

\section{To cite this article:}

Basant K. Jha, Michael O. Oni. Laminar Convection in a Uniformly Heated Vertical Porous Channel Revisited. Advances in Applied Sciences. Vol. 2, No. 3, 2017, pp. 28-32. doi: 10.11648/j.aas.20170203.11

Received: March 2, 2017; Accepted: April 25, 2017; Published: July 5, 2017

\begin{abstract}
This work revisited the mixed convection flow formation in a uniformly heated vertical porous channel filled with porous material as discussed by Chandrasekhara and Nayrayanan [11]. Using perturbation method as well as numerical solution, Chandrasekhara and Nayrayanan [11] discussed the behavior of the fluid as well as rate of heat transfer. This methods are known not to be exact solution. In this work, we derived an exact solution using D'Alembert's method and corrected some results obtained in [11]. To justify the accuracy of the present method, we used the implicit finite difference method (IFDM). Result shows that D'Alembert's method is more efficient, effective and thus a promising tool for finding exact solution for coupled equations.
\end{abstract}

Keywords: Laminar, Uniform Heating, Vertical Porous Channel, D’Alembert Approach

\section{Introduction}

The analysis of heat and mass transfer in porous media has become an interesting area of research due to its varied applications both in industrial and scientific applications such as extrusion of polymers, cooling of metallic plates, aerodynamics plastic extrusion, geothermal reservoirs, glass blowing and fiber spinning, drying of porous solids, thermal insulation, petroleum resources and many others. Physically, fluid flow nested with porous medium is a common phenomenon in nature such as transport of water in living plants, trees and fertilizers or wastes in soil. This problem is motivated by its engineering applications as: convection in the Earth crust, flows in soils, aquifers, storage of agriculture products and so on.

Free convection between heated vertical parallel plates is the most frequently used configuration in convection air cooling of electronic equipment. The passive character of cooling by natural convection makes it very attractive for applications in electronic devices. A review of the literature shows that laminar free convection in vertical channel has been studied by several authors: Elenbaas [1] led the first experimental study which was used in the follow as reference solution. Bodoï and Österle [2] obtained the first numerical solution of the natural convection in vertical channel. Their results agree with Elenbaas. In order to increase the cooling requirements, researches for methods to improve the heat transfer parameters or to analyze standard configurations to carry out optimal geometrical parameters for a better heat transfer rate are crucial [3-9].

For the sake of completeness, few studies had concerned the mixed convection regime: Mishra et al. [10] investigated fully developed natural and forced convection flow of an incompressible viscous fluid between two vertical walls filled with a porous material and saturated with the same fluid. The Brinkman Darcy model was used to analyze the flow in the porous domain. Flow formation changes from forced convection dominated to free convection dominated as Rayleigh number increases. Chandrasekhara and Radha [11] studied two situations of laminar convection in a uniformly heated vertical porous channel, namely steady heating of ascending cold fluid and steady cooling of ascending hot fluid. They concluded that increase in porosity parameter decreases both the velocity, temperature and mass flow rate but increase the rate of heat transfer.

The purpose of this paper is to present an exact solution to laminar convection in a uniformly heated vertical porous channel proposed by Chandrasekhara [11] by the use of D'Alembert's approach. Closed form expressions are obtained for fluid temperature, velocity and rate of heat transfer.

\section{Mathematical Analysis}

Consider a steady laminar fully developed mixed convection flow of an incompressible, viscous fluid in a 
vertical channel filled with porous material. Following the model and assumptions of Chandrasekhara [11], the momentum and energy equations and their respectively boundary conditions in dimensionless form are as follows:

$$
\begin{aligned}
& \frac{d^{2} U}{d Y^{2}}-\sigma^{2} U=-N+R_{a} \Theta \\
& \frac{d^{2} \Theta}{d Y^{2}}-U=0 \\
& \frac{d U}{d Y}=\frac{d \Theta}{d Y}=0 \text { at } Y=0 \\
& U=\Theta=0 \text { at } Y=1
\end{aligned}
$$

where $\sigma, N$ and $\mathrm{R}_{\mathrm{a}}$ are respectively porosity parameter, dimensionless pressure gradient and Rayleigh number.

Using D'Alembert's method as used by $[12,13]$, we have;

$$
\frac{\mathrm{d}^{2}[\mathrm{AU}+\Theta]}{\mathrm{dY^{2 }}}-\left[\mathrm{U}\left(1-\mathrm{A} \sigma^{2}\right)-\mathrm{R}_{\mathrm{a}} \mathrm{A} \Theta\right]=-\mathrm{NA}
$$

Also the boundary conditions (eq. 3) become

$$
\begin{gathered}
\mathrm{AU}(-1 / 2)+\Theta(-1 / 2)=-\Theta_{0} \\
\mathrm{AU}(1 / 2)+\Theta(1 / 2)=1-\Theta_{0}
\end{gathered}
$$

where

$$
\begin{aligned}
& A=\frac{\left(A \sigma^{2}-1\right)}{R_{a} A} \\
& \delta^{2}=R_{a} A
\end{aligned}
$$

Solving Eq. (4) and applying the boundary conditions Eq.(5), we have;

$$
\mathrm{AU}+\Theta=\frac{\mathrm{NA}}{\delta^{2}}\left[1-\frac{\cosh \delta \mathrm{Y}}{\cosh \delta}\right]
$$

Replacing $\mathrm{A}$ with $\mathrm{A}_{1}$ and $\mathrm{A}_{2}$ one after the other in Eqs. (6) - (8), we obtain

$$
\begin{aligned}
& A_{1} U+\Theta=\frac{N A_{1}}{\delta_{1}{ }^{2}}\left[1-\frac{\cosh \delta_{1} Y}{\cosh \delta_{1}}\right] \\
& A_{2} U+\Theta=\frac{N_{2}}{\delta_{2}{ }^{2}}\left[1-\frac{\cosh \delta_{2} Y}{\cosh \delta_{2}}\right]
\end{aligned}
$$

Where $A_{1}$ and $A_{2}$ are the roots of Eq. (6) and are defined as

$$
\mathrm{A}_{1}=\frac{\sigma^{2}+\sqrt{\sigma^{4}-4 R_{a}}}{2 R_{a}}, \mathrm{~A}_{2}=\frac{\sigma^{2}-\sqrt{\sigma^{4}-4 R_{a}}}{2 R_{a}}, \delta_{1}=\sqrt{R_{a} A_{1}}
$$

and

$$
\delta_{2}=\sqrt{R_{a} A_{2}}
$$

Solving Eqs. (9) and (10), we obtain the velocity field and the temperature distribution respectively as:

Case I: $A_{1} \neq A_{2}$

$$
\mathrm{U}(\mathrm{Y})=\frac{\mathrm{N}}{\mathrm{R}_{\mathrm{a}}\left[\mathrm{A}_{1}-\mathrm{A}_{2}\right]}\left[\frac{\cosh \delta_{2} \mathrm{Y}}{\cosh \delta_{2}}-\frac{\cosh \delta_{1} \mathrm{Y}}{\cosh \delta_{1}}\right]
$$

$\Theta(Y)=\frac{N}{R_{a}\left[A_{2}-A_{1}\right]}\left[\left(A_{2}-A_{1}\right)+A_{1} \frac{\cosh \delta_{2} Y}{\cosh \delta_{2}}-A_{2} \frac{\cosh \delta_{1} Y}{\cosh \delta_{1}}\right]$

Next, the dimensionless rate of heat transfer represented by Nusselt number following Chandrasekhara and Nayrayanan [11] is defined as

$$
\begin{gathered}
N u=\frac{\left.\frac{d \Theta}{d Y}\right|_{Y=1}}{\int_{0}^{1} \Theta(Y) d Y} \\
N u=\frac{\delta_{1} \delta_{2}\left[\mathrm{~A}_{1} \delta_{2} \tanh \left(\delta_{2}\right)-\mathrm{A}_{2} \delta_{1} \tanh \left(\delta_{1}\right)\right]}{\delta_{1} \delta_{2}\left(\mathrm{~A}_{2}-\mathrm{A}_{1}\right)+\mathrm{A}_{1} \delta_{1} \tanh \left(\delta_{2}\right)-\mathrm{A}_{2} \delta_{2} \tanh \left(\delta_{1}\right)}
\end{gathered}
$$

\begin{tabular}{|c|c|c|c|c|c|c|c|c|c|c|}
\hline \multirow[b]{2}{*}{$\sigma$} & \multicolumn{2}{|c|}{$\begin{array}{l}\text { Regular Perturbation } \\
\text { method ref [11] }\end{array}$} & \multicolumn{2}{|c|}{$\begin{array}{l}\text { Single Perturbation } \\
\text { method ref [11] }\end{array}$} & \multicolumn{2}{|c|}{$\begin{array}{l}\text { Semi numerical method } \\
\text { Ref [11] }\end{array}$} & \multicolumn{2}{|c|}{ Present work (Exact solution) } & \multicolumn{2}{|l|}{ IFDM } \\
\hline & $\mathbf{U}(\mathbf{0})$ & $\boldsymbol{\Theta}(\mathbf{0})$ & $\mathbf{U}(\mathbf{0})$ & $\boldsymbol{\Theta}(\mathbf{0})$ & $\mathbf{U}(\mathbf{0})$ & $\boldsymbol{\Theta}(\mathbf{0})$ & $\mathbf{U}(\mathbf{0})$ & $\boldsymbol{\Theta}(\mathbf{0})$ & $\mathbf{U}(\mathbf{0})$ & $\boldsymbol{\Theta}(\mathbf{0})$ \\
\hline 5 & 0.35943 & 0.1603 & - & - & 0.3614 & 0.1640 & 0.3614 & 0.1640 & 0.36316 & 0.171316 \\
\hline 10 & 0.0975 & 0.04605 & - & - & 0.0977 & 0.04607 & 0.0971 & 0.04607 & 0.09764 & 0.048023 \\
\hline 25 & 0.01592 & 0.00763 & 0.0160 & 0.00763 & 0.01593 & 0.007629 & 0.01593 & 0.007629 & 0.01594 & 0.007948 \\
\hline 50 & 0.0040 & 0.0020 & 0.00396 & 0.00197 & - & - & 0.00399 & 0.00191 & 0.00340 & 0.001997 \\
\hline 70 & 0.00204 & 0.00098 & 0.00204 & 0.00097 & - & - & 0.002039 & 0.000978 & 0.002040 & 0.001020 \\
\hline
\end{tabular}

Case II: $A_{1}=A_{2}$

By taking the limiting case $A_{2} \rightarrow A_{1}$, we obtained respectively the following expressions for velocity, temperature and rate of heat transfer.

$\mathrm{U}(\mathrm{Y})=\frac{\mathrm{N} \operatorname{sech}\left(\delta_{1}\right)}{2 \sqrt{\mathrm{AR}_{\mathrm{a}}}}\left[\tanh \left(\delta_{1}\right) \cosh \left(\delta_{1} \mathrm{Y}\right)-\mathrm{Y} \sinh \left(\delta_{1} \mathrm{Y}\right)\right]$

\section{Results and Discussion}

From equations (11-17), the velocity, temperature and rate of heat transfer are seen to be govern by porosity parameter $(\sigma)$, dimensionless pressure gradient $(N)$ and Rayleigh number $\left(\mathrm{R}_{\mathrm{a}}\right)$.

Table 1. Values of $U$ and $\Theta$ for various values of $\sigma$ obtained through different methods for $R_{a}=5, N=10$. 
Table 1 presents the numerical comparison of the present method (exact solution) with approximate methods (perturbation as well as numerical solution) used in literature [11]. As expected, it is observed that both velocity and temperature decreases with increase in porosity parameter $\sigma$. We justify the accuracy of this present method by using implicit finite difference method (IFDM) and this gives a good justification. Table 2 gives comparison of regular perturbation method, exact solution and implicit finite difference method (IFDM). It is seen that both velocity and temperature increases with increase in the dimensionless pressure gradient $N$.

Table 2. Values of $U$ and $\Theta$ for various values of $N$ obtained through different methods for $R_{a}=100, \sigma=10$.

\begin{tabular}{lllllll}
\hline & $\begin{array}{l}\text { Regular } \\
\text { Perturbation } \\
\text { Method ref [11] }\end{array}$ & \multicolumn{2}{l}{$\begin{array}{l}\text { Present work } \\
\text { (Exact solution) }\end{array}$} & IFDM & \\
\hline $\boldsymbol{N}$ & $\mathbf{U}(\mathbf{0})$ & $\boldsymbol{\Theta}(\mathbf{0})$ & $\mathbf{U}(\mathbf{0})$ & $\boldsymbol{\Theta}(\mathbf{0})$ & $\mathbf{U}(\mathbf{0})$ & $\boldsymbol{\Theta ( 0 )}$ \\
\hline \multirow{1}{*}{1} & 0.00221 & 0.0011 & 0.00221 & 0.00112 & 0.00221 & 0.00112 \\
& 96 & 26 & 97 & 69 & 97 & 81 \\
10 & 0.02219 & 0.0112 & 0.02219 & 0.01126 & 0.02219 & 0.01126 \\
10 & 6 & 69 & 66 & 90 & 68 & 82 \\
0 & 0.22196 & 0.1126 & 0.22196 & 0.11269 & 0.22196 & 0.11268 \\
\hline
\end{tabular}

Table 3. Values of $U$ and $\Theta$ for various values of $R_{a}$ obtained through different methods for $N=10, \sigma=5, Y=0.2$.

\begin{tabular}{|c|c|c|c|c|c|c|}
\hline \multirow[b]{2}{*}{$\boldsymbol{R}_{a}$} & \multicolumn{2}{|c|}{$\begin{array}{l}\text { Regular } \\
\text { Perturbation } \\
\text { Method ref [11] }\end{array}$} & \multicolumn{2}{|c|}{$\begin{array}{l}\text { Present work } \\
\text { (Exact solution) }\end{array}$} & \multicolumn{2}{|l|}{ IFDM } \\
\hline & $\mathrm{U}(\mathbf{0 . 2 )}$ & $\Theta(0.2)$ & $\mathrm{U}(\mathbf{0 . 2 )}$ & $\Theta(0.2)$ & $\mathrm{U}(0.2)$ & $\Theta(0.2)$ \\
\hline-5 & - & 0.42654 & 0.4265 & 0.1906 & $\begin{array}{l}0.4265 \\
28\end{array}$ & $\begin{array}{l}0.1905 \\
40\end{array}$ \\
\hline-20 & - & 0.58702 & 0.5752 & 0.2511 & $\begin{array}{l}0.5751 \\
77\end{array}$ & $\begin{array}{l}0.2510 \\
44\end{array}$ \\
\hline-50 & - & 1.6244 & 1.6244 & 0.6789 & $\begin{array}{l}1.5683 \\
58\end{array}$ & $\begin{array}{l}0.6463 \\
98\end{array}$ \\
\hline-100 & - & -0.37884 & -0.9818 & $\begin{array}{l}- \\
0.37884 \\
\end{array}$ & $\begin{array}{l}223.11 \\
42\end{array}$ & $\begin{array}{l}64.287 \\
92\end{array}$ \\
\hline
\end{tabular}

Effects of Rayleigh number $R_{a}$ on velocity and temperature of the fluid is presented in table 3 and it is observed that increasing $R_{a}$ increases the velocity and temperature for $R_{a} \gg-100$. Table 4 gives the rate of heat transfer $(N u)$ at different values of $R_{a}$ for steady cooling of ascending hot fluid. It is seen that the rate of heat transfer decreases with increase in $-R_{a}$ for $R_{a} \gg-1000$

Table 4. Values of Nusselt number of upflow cooled for selected values of $R_{a}$ obtained through different methods for $N=10, \sigma=5$.

\begin{tabular}{lll}
\hline & $\begin{array}{l}\text { Regular Perturbation } \\
\text { Method ref [11] }\end{array}$ & $\begin{array}{l}\text { Present work (Exact } \\
\text { solution) }\end{array}$ \\
\hline $\boldsymbol{R}_{\boldsymbol{a}}$ & $\boldsymbol{N u}$ Upflow cooled & $\boldsymbol{N u}$ Upflow cooled \\
\hline-5 & 2.6471 & 2.6418 \\
-50 & 2.524 & 2.5188 \\
-100 & 2.3744 & 2.3697 \\
\hline
\end{tabular}

${ }^{1}$ Tables 3 and 4 on p. 376 of Chandrasekhara and Nayrayanan [11], $R_{a}$ should be $-R_{a}$

Values for $\Theta(0.2)$ in table 3 of [11] should be for $U(0.2)$ for $R_{a}=-5,-20,-50$

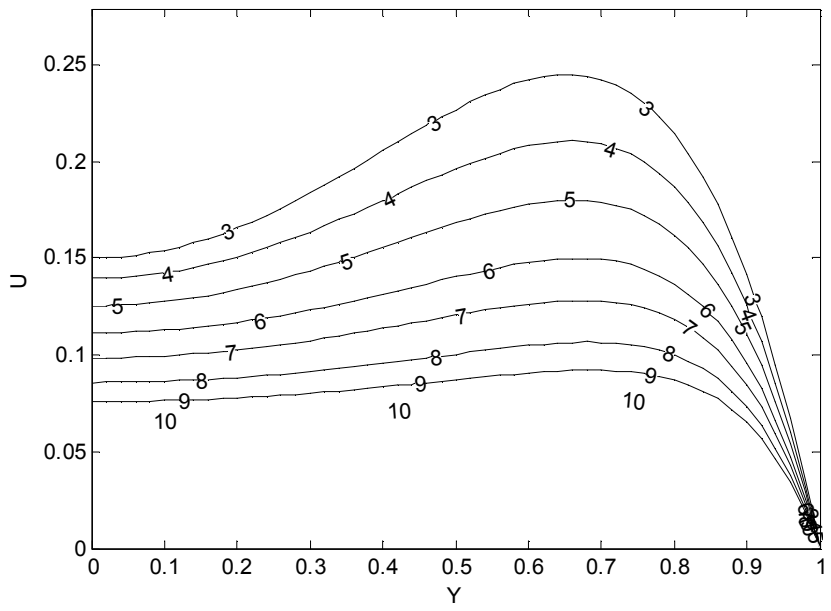

Figure 1. Velocity profile for different values of $\sigma$ at $R_{a}=100, N=10$.

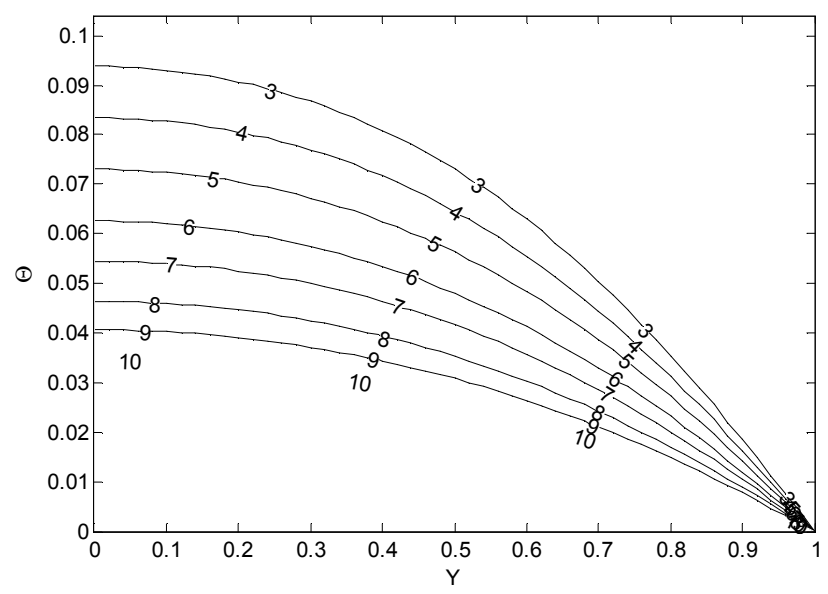

Figure 2. Temperature distribution for different values of $\sigma$ at $R_{a}=$ $100, N=10$.

Figures 1-3 depict the effects of porosity parameter $\sigma$ on the velocity profiles, temperature distributions and rate of heat transfer $(\mathrm{Nu})$ respectively at fixed value of Rayleigh number $\left(R_{a}\right)$ and pressure gradient parameter $(N)$ in the channel.

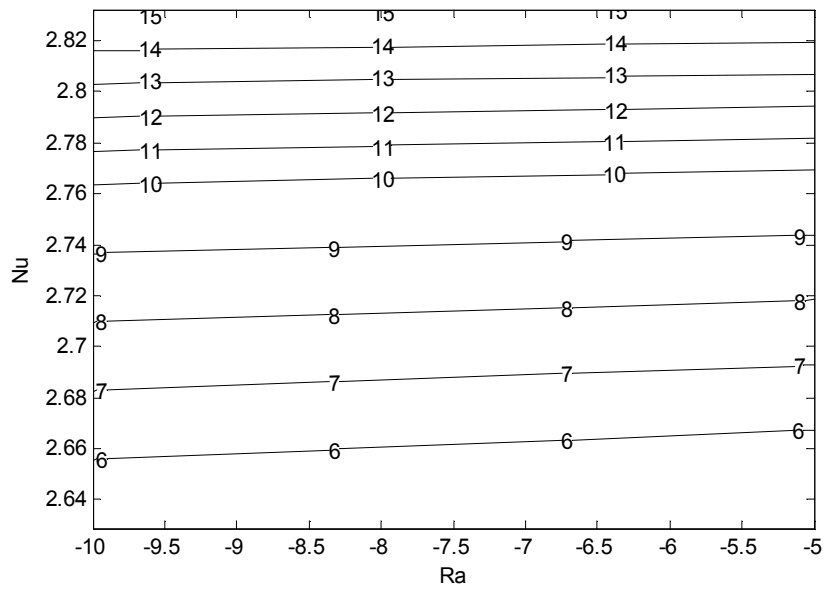

Figure 3. Variation of Nusselt number for different values of $\sigma$ and $R_{a}$, at $N=10$. 
From these figures, velocity as well as temperature of the fluid is seen to decrease with increase in porosity parameter. This is physical true since increase in the size of the particles hinders the flow and temperature field. On the hand, the rate of heat transfer is found to increase with increase in porosity parameter.

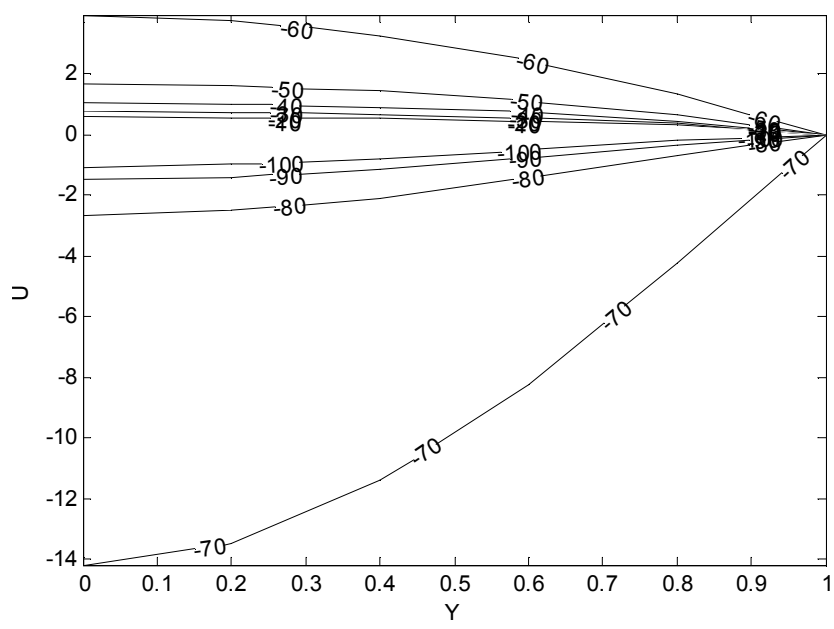

Figure 4. Velocity profile for different values of $R_{a}$ at $\sigma=5, N=10$.

The effects of Rayleigh number $\left(R_{a}\right)$ on the velocity and temperature of steady cooling of ascending hot fluid at constant value of porosity parameter $\sigma$ and pressure gradient parameter $(N)$ is depicted in Figs. 4 and 5 respectively. For $R_{a} \geq-60$, it is observed that the velocity and temperature increases with increase in $R_{a}$ whereas there is a flow reversal and adverse temperature gradient whenever $R_{a}<-60$. This can also be seen in Table 3 which corresponds with the findings of Chandrasekhara [11]

Figures 6 and 7 plot the effects of pressure gradient parameter $(N)$ on the velocity and temperature of fluid respectively at fixed value of porosity parameter $\sigma$ and positive Rayleigh number. It is observed that both the velocity and temperature of the fluid increases with increase in $(N)$. This is because the pressure gradient is applied in the direction of the fluid and therefore aid flow formation.

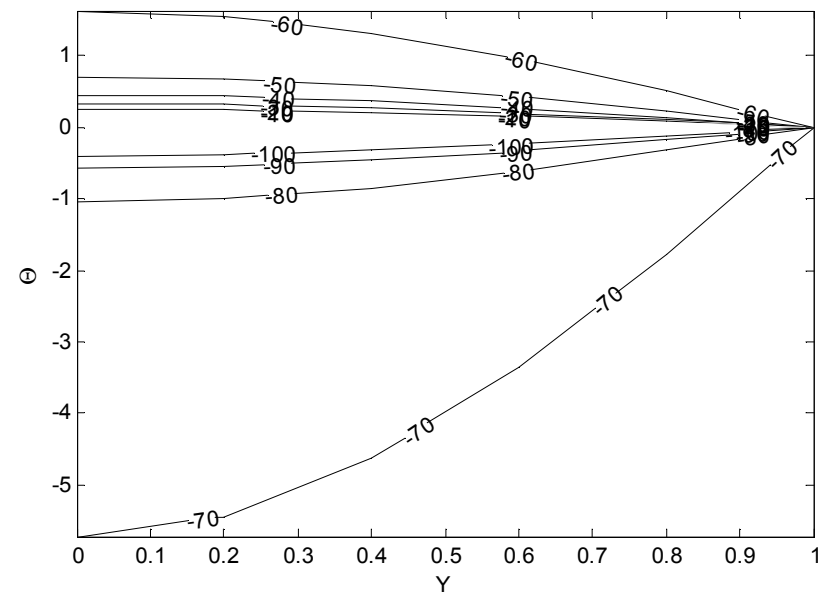

Figure 5. Temperature distribution for different values of $R_{a}$ at $\sigma=5, N=$ 10 .

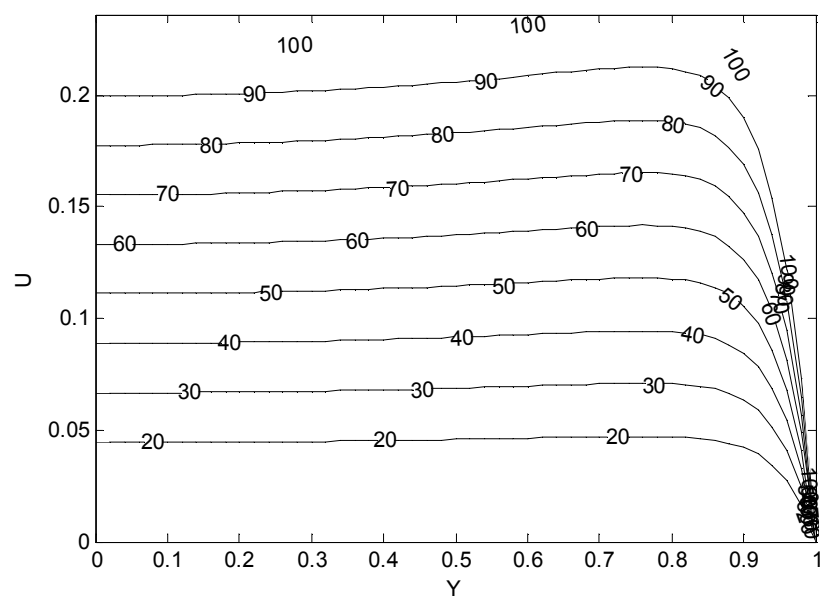

Figure 6. Velocity profile for different values of $N$ at $\sigma=20, R_{a}=100$.

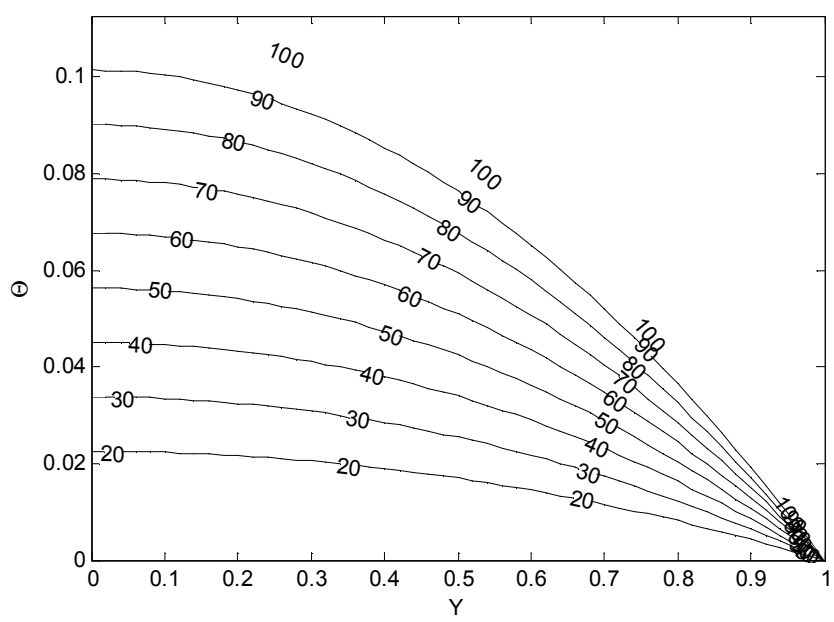

Figure 7. Temperature distribution for different values of $N$ at $\sigma=20, R_{a}=$ 100 .

\section{Conclusions}

An exact solution of laminar convection in a uniformly heated vertical porous channel is obtained in this paper using D'Alembert's method. Based on the numerical values obtained from the exact solution, the following conclusions are drawn:

1. D'Alembert method is an effective, analytical and easy method of solution. This is based on the numerical values obtained in Tables $(1-4)$. In addition, unlike ref. [11] where they used four cases which were solved differently through rigorous calculations and approximations; D'Alembert's method generalizes the solution for all cases and presents a closed form expression for fluid temperature, velocity and Nusselt number.

2. Velocity as well as temperature decreases with increase in porosity parameter while the rate of heat transfer increases. This finding corresponds with Chandrasekhara [11]

3. Pressure gradient parameter increases both the velocity and temperature of the fluid for positive Rayleigh number in the channel. 


\section{List of Symbols}

$N \quad$ dimensionless pressure gradient

$\mathrm{Nu} \quad$ Nusselt number

$R_{a} \quad$ Rayleigh number

U dimensionless velocity

$Y \quad$ dimensionless coordinate

\section{Greek Symbols}

$\sigma \quad$ porosity parameter

$\Theta \quad$ dimensionless temperature

\section{References}

[1] W. Elenbaas, Heat Dissipation of Parallel Plates by Free convection,Physica, vol. 9, n 1, pp.1-28, 1942.

[2] J. R. Bodoia and J. F. Osterle, The Development of Free ConvectionBetween Heated Vertical Plates, J. of Heat Transfer, Trans. ASME,Series C, vol. 84, n 1 , pp. 40-44, 1962.

[3] S. J. Kim, S. W. Lee, Air Cooling Technology for Electronic Equipment,CRC Press, Boca Raton, FL, 1996.

[4] A. Bejan, Shape and Structure from Engineering to Nature, CambridgeUniversity Press, New York, 2000.

[5] G. A. Ledezma, A. Bejan, Optimal geometric arrangement of staggeredvertical plates in natural convection, ASME J. Heat Transfer 119; pp. 700-708, 1997.
[6] S. Sathe, B. Sammakia, A review of recent developments in somepractical aspects of air-cooled electronic packages, ASME J. HeatTransfer 120; pp. 830-839, 1998.

[7] A. Bejan, A. K. da Silva, S. Lorente, Maximal heat transfer density invertical morphing channels with natural convection, Numer. HeatTransfer A 45; pp. 135-152, 2004.

[8] A. Auletta, O. Manca, B. Morrone, V. Naso, Heat transfer enhancementby the chimney effect in a vertical isoflux channel, Int. J. Heat MassTransfer 44 pp. 4345-4357, 2001.

[9] A. K. da Silva, L. Gosselin, Optimal geometry of L- and Cshapedchannels for maximum heat transfer rate in natural convection, Int. J. Heat Mass Transfer 48 pp. 609-620, 2005.

[10] Mishra, A., Paul, T., and Singh, A.; Mixed convection flow in a porous medium bounded by two vertical walls, ForschungimIngenieurwesen, V.67, pp. 198-205 (2002).

[11] Chandrasekhara BC., Radha N.; Laminar convection in a uniformly heated vertical porous channel, Indian Journal of Technology, 27 pp. 371-376 (1989).

[12] B. K. Jha, C. A. Apere, (2013) Unsteady MHD two-phase Couette flow of fluid-particle suspension. Applied Mathematical Modelling 37:1920-1931.

[13] Z. Recebli, H. Kurt, Two-phase steady flow along a horizontal glass pipe in the presence of magnetic and electric field, Int. J. Heat Fluid Flow, 29; 263-268 (2008). 